\title{
Brucella suis Infection in Dog Fed Raw Meat, the Netherlands
}

\section{Marloes A.M. van Dijk, Marc Y. Engelsma, Vanessa X.N. Visser, Marcel A.H. Spierenburg, Marjolijn E. Holtslag, Peter T.J. Willemsen, Jaap A. Wagenaar, Els M. Broens, ${ }^{1}$ Hendrik I.J. Roest ${ }^{1}$}

A Brucella suis biovar 1 infection was diagnosed in a dog without typical exposure risks, but the dog had been fed a raw meat-based diet (hare carcasses imported from Argentina). Track and trace investigations revealed that the most likely source of infection was the dog's raw meat diet.

$\mathrm{E}$ xposure risks for Brucella suis infection typically include contact with wildlife or livestock, breeding, and travel to brucellosis-endemic areas. We report a case of $B$. suis infection in a dog for which the risk was determined to be a raw meat-based diet.

\section{The Case}

In November 2016, a 6-year-old, intact, male American Staffordshire terrier was admitted to a primary care veterinary clinic in the Netherlands, where fever, ascites, and epididymitis/orchitis were detected. Because clinical signs did not improve after a 5-day course of amoxicillin/clavulanic acid (12.5 mg/kg 2×/d), the dog was neutered. During surgery, purulent exudate from the epididymis was noted; this exudate and abdominal fluid were collected and submitted to a routine veterinary diagnostic laboratory. Both samples yielded bacterial growth that was identified by matrix-assisted laser desorption/ionization time-of-flight (MALDI-TOF) mass spectrometry (Bruker Daltonics, Bremen, Germany) as Brucella spp. The Dutch National Reference Laboratory identified the isolate by MALDI-TOF mass spectrometry (with an in-house extended database) as Brucella suis biovar 1, and the EU reference laboratory confirmed this phenotypically (1). One isolate was sequenced and molecularly characterized in silico by multilocus variable-number tandem-repeat analysis (MLVA) as Ms Bruce 06/08/11/12/42/43/45/55/18/19/21/04/07/09/16/30:

Author affiliations: Utrecht University, Utrecht, the Netherlands (M.A.M. van Dijk, J.A. Wagenaar, E.M. Broens); Wageningen Bioveterinary Research, Lelystad, the Netherlands (M.Y. Engelsma, M.E. Holtslag, P.T.J. Willemsen, J.A. Wagenaar, H.I.J. Roest); Netherlands Food and Consumer Product Safety Authority, Utrecht (V.X.N. Visser, M.A.H. Spierenburg)
2/3/6/10/4/1/5/2/4/38/9.5/5/4/8/5/3 and by multilocus sequence typing (MLST) as sequence type (ST) 14 (2-4).

After diagnosis confirmation, serum and urine samples were collected from the dog. Serologic testing for B. suis yielded a positive result by microscopic agglutination test (MAT; $>120 \mathrm{IU} / \mathrm{mL}$ ) and rose bengal test $(4,5)$. Serologic test results for $B$. canis (serum agglutination test $<50 \mathrm{IU} /$ $\mathrm{mL})(1)$ and bacteriologic culture of a urine sample were negative. Despite treatment with doxycycline $(10 \mathrm{mg} /$ $\mathrm{kg} 1 \times / \mathrm{d}$ for 14 days starting 3 days after neuter), the $\operatorname{dog}$ did not recuperate and because of the poor prognosis was euthanized. Postmortem examination of the dog was performed, and samples from kidney, spleen, prostate, liver, and abdominal lymph nodes were tested by PCR (4). Only the prostate yielded a positive result for Brucella spp.

Because brucellosis is notifiable in the Netherlands, the Incidence Crisis Centre of the Netherlands Food and Consumer Product Safety Authority was notified. The Centre started investigations to track potential transmission and trace the source of infection. The owners of the index dog were asked to list all dogs that had had frequent contact with their dog during the previous $2-3$ months. From the 5 contact dogs identified, blood samples were collected (twice, 4 weeks apart) for serologic testing (MAT and rose bengal) and urine samples were collected for bacteriologic culture. Blood from 1 contact dog yielded a weakly positive result for $B$. suis antibodies (MAT $30 \mathrm{IE} / \mathrm{mL}$; rose bengal negative) at both collection times. An acute infection in this dog was considered unlikely because no seroconversion was detected. All other dogs yielded negative serologic results. All urine samples were bacteriologically negative.

The owners of the index dog reported no relevant exposure risks except that the dog was fed a raw meat-based diet (usually commercial mixed raw feed and in June-July 2016 unprocessed heads of hares, all from the same supplier). Because raw meat consumption has been associated with $B$. suis infections in dogs $(6,7)$, the feed was considered a potential source of infection. In December 2016, the index dog owner provided leftovers of the commercial mixed raw feed, which we tested by PCR for the presence of porcine DNA and Brucella spp.; results for both were negative. The investigators visited the raw feed supplier and sampled a (not yet marketed) 30,000-kg batch of hare carcasses imported from Argentina. Of 40 representative

${ }^{1}$ These senior authors contributed equally to this article. 
samples, 2 yielded a positive PCR result for Brucella spp. and were subsequently cultured. Colonies from 1 sample were confirmed by MALDI-TOF mass spectrometry (with an in-house extended database) to be $B$. suis biovar 1 . One isolate was sequenced and molecularly characterized in silico by MLVA and MLST (ST14) (2-4). The isolates from the index dog and from the batch of hare carcasses showed high similarity (only 1 locus difference in the MLVA Ms07: 4 repeats dog isolate; 6 repeats hare isolate). Similarity with 24 closely related reference isolates from a public database (http://microbesgenotyping.i2bc.parissaclay.fr/) was much lower (Figure).

\section{Conclusions}

This $B$. suis biovar 1 infection in a dog in the Netherlands was linked to its commercial raw meat-based diet. Canine infections with this biovar have been documented in B. suis biovar 1-endemic areas (e.g., Australia and Latin America), mostly associated with exposure to feral pigs or consumption of raw feral pig meat $(6,7)$. In the case we report, the $B$. suis biovar 1 infection most likely originated from hare carcasses imported from Argentina into the Netherlands. B. suis biovar 1 is endemic to Latin America and has been isolated from hares (7-9). The dog showed clinical

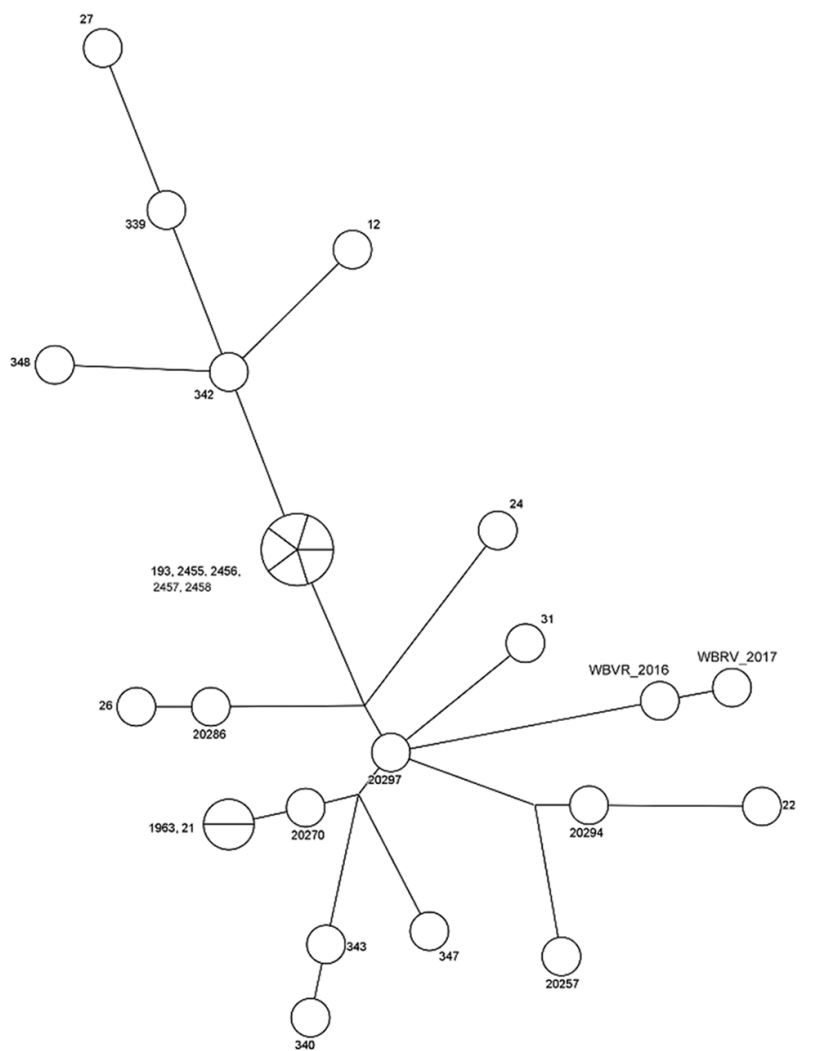

signs $\approx 4$ months after it had been fed raw hare heads from a supplier of commercial raw feed. The presence of $B$. suis biovar 1 in another batch of hare carcasses from the same supplier makes foodborne transmission highly likely. The genotypic similarity between the isolates from the dog and the feed and the fact that the supplier imported multiple batches from the same slaughter plant in Argentina during the preceding months confirms the feed as the most probable source of infection.

This report illustrates possible implications of the global trade of raw meat. Importation of hare carcasses, whether or not approved for human consumption, from countries outside the European Union into the European Union is legal. Because the aforementioned batches of hare carcasses from Argentina were approved for human and animal consumption, humans and other animals were potentially at risk when handling or consuming meat products from these batches.

Medical microbiologists of the Municipal Health Service assessed the zoonotic risks for all persons who had come in contact with the dog or with samples from the dog or hare carcasses. Five laboratory technicians who had been exposed to pure cultures (before bacterial identification) were given postexposure prophylaxis and tested for

\begin{tabular}{|c|c|c|c|c|}
\hline Key & Strain ID & Host & Isolated in & Year \\
\hline 12 & REF 1330 & Swine & USA & NA \\
\hline 21 & BCCN\#87-67a & Unknown & China & 1987 \\
\hline 22 & BCCN\#87-68 & Unknown & Portugal & 1987 \\
\hline 24 & BCCN\#87-72 & Unknown & Denmark & 1987 \\
\hline 26 & BCCN\#87-87 & Unknown & Poland & 1987 \\
\hline 27 & BCCN\#87-88 & Unknown & Poland & 1987 \\
\hline 31 & BCCN\#98-43 & Swine & Argentina & 1998 \\
\hline 193 & BCCN\#03-27 & Horse & Croatia & 2003 \\
\hline 339 & S-88 & Horse & Croatia & 2003 \\
\hline 340 & $S-90$ & Wild boar & Croatia & 1992 \\
\hline 342 & S-94 & Wild boar & Croatia & 2003 \\
\hline 343 & S-97 & Swine & Croatia & 1994 \\
\hline 347 & S-104 & Hare & Croatia & 1980 \\
\hline 348 & S-105 & Hare & Croatia & 1980 \\
\hline 1963 & N11 & Cattle & China & 2009 \\
\hline 2455 & INRA03-26 & Swine & France & 2003 \\
\hline 2456 & AFSSA-03/3081-2 & Caprid & Croatia & 2003 \\
\hline 2457 & AFSSA-04/115 & Hare & France & 2004 \\
\hline 2458 & AFSSA-04/3025-3 & Swine & Croatia & 2004 \\
\hline 20257 & B05-1335_IA_SwineD & Swine & USA & 2016 \\
\hline 20270 & B11-0438_FL_Cow & Cattle & USA & 2016 \\
\hline 20286 & B13-0198_TX_Feralpig & Feral pig & USA & 2016 \\
\hline 20294 & B94-0444_TX_Swine & Swine & USA & 2016 \\
\hline 20297 & B95-0512_OH_Dog & Dog & USA & 2016 \\
\hline WBVR_2016 & WBVR_2016 & Dog & Netherlands & 2016 \\
\hline WBVR_2017 & WBVR_2017 & Hare & Netherlands & 2017 \\
\hline
\end{tabular}

Figure. Maximum parsimony analysis on MLVA-16 (multilocus variable-number tandem-repeat analysis) of genotypes from 2 recent Brucella suis biovar 1 isolates from the Netherlands (WBVR2016 from a dog and WBVR2017 from hare carcasses) in conjunction with $B$. suis biovar 1 strains of the highest similarity from a public database (http://microbesgenotyping.i2bc.paris-saclay.fr/) with 521 entries of $B$. suis. NA, not available. 
seroconversion to $B$. suis (postexposure weeks $2,4,6$, and $24)$ according to national guidelines (10). To our knowledge, no human infections were linked to this case.

$B$. suis biovar 1 is a potential threat to the pig farming industry because introduction of $B$. suis into pig herds can have substantial economic consequences (11). A striking detail is that the last $B$. suis infection in pigs in the Netherlands (1969) was associated with swill feeding of hares imported from Argentina (12).

In response to our findings, preventive measures were implemented (e.g., sampling of imported raw meat and communication of risk to international authorities and rawfeed suppliers). This case stresses the microbiological risks for humans and animals of feeding raw meat-based diets, which has become increasingly popular among pet owners (13). This case also highlights the need for a One Health approach because $B$. suis biovar 1 is a zoonotic agent and can cause severe infections in humans $(14,15)$.

\section{Acknowledgments}

We thank the dog owners for their cooperation and Nicole Helmond, Sylvia Bruin, Anky Schoormans, Frank Harders, Annemieke Dinkla, Alieda van Essen, Yvonne Dijkstra, Rob Buijs, and Evelien Kern for their excellent technical assistance and Maryne Jaÿ for confirmation of the strain.

Surveillance of zoonotic pathogens in companion animals in the Netherlands was funded by the Dutch Ministry of Agriculture, Nature and Food Quality and the Dutch Ministry of Health, Welfare and Sport. Confirmation and laboratory work done at Wageningen Bioveterinary Research was financed by the Ministry of Agriculture, Nature and Food Quality (project no. WOT-01-002-006.01).

\section{About the Author}

Dr. van Dijk is a doctor of veterinary medicine enrolled in a residency program in veterinary microbiology at the Department of Infectious Diseases and Immunology, Faculty of Veterinary Medicine, Utrecht University. She is involved in of the surveillance of zoonotic pathogens in companion animals in the Netherlands.

\section{References}

1. World Organisation for Animal Health. Brucellosis (Brucella abortus, B. melitensis and B. suis) [cited 2017 Nov 10]. http://www.oie.int/en/international-standard-setting/terrestrialmanual/access-online/

2. Le Flèche P, Jacques I, Grayon M, Al Dahouk S, Bouchon P, Denoeud F, et al. Evaluation and selection of tandem repeat loci for a Brucella MLVA typing assay. BMC Microbiol. 2006;6:9. http://dx.doi.org/10.1186/1471-2180-6-9

3. Whatmore AM, Perrett LL, MacMillan AP. Characterisation of the genetic diversity of Brucella by multilocus sequencing. BMC Microbiol. 2007;7:34. http://dx.doi.org/10.1186/1471-2180-7-34

4. Maio E, Begeman L, Bisselink Y, van Tulden P, Wiersma L, Hiemstra S, et al. Identification and typing of Brucella spp. in stranded harbour porpoises (Phocoena phocoena) on the Dutch coast. Vet Microbiol. 2014;173:118-24. http://dx.doi.org/10.1016/ j.vetmic.2014.07.010

5. Germeraad EA, Hogerwerf L, Faye-Joof T, Goossens B, van der Hoek W, Jeng M, et al. Low seroprevalence of brucellosis in humans and small ruminants in the Gambia. PLoS One. 2016;11:e0166035. http://dx.doi.org/10.1371/journal.pone.0166035

6. Mor SM, Wiethoelter AK, Lee A, Moloney B, James DR, Malik R. Emergence of Brucella suis in dogs in New South Wales, Australia: clinical findings and implications for zoonotic transmission. BMC Vet Res. 2016;12:199. http://dx.doi.org/ 10.1186/s12917-016-0835-0

7. Lucero NE, Ayala SM, Escobar GI, Jacob NR. Brucella isolated in humans and animals in Latin America from 1968 to 2006. Epidemiol Infect. 2008;136:496-503. http://dx.doi.org/10.1017/ S0950268807008795

8. García-Yoldi D, Le Fleche P, De Miguel MJ, Muñoz PM, Blasco JM, Cvetnic Z, et al. Comparison of multiple-locus variable-number tandem-repeat analysis with other PCR-based methods for typing Brucella suis isolates. J Clin Microbiol. 2007;45:4070-2. http://dx.doi.org/10.1128/JCM.01096-07

9. Fort M, Baldone V, Fuchs L, Giménez H, Rojas M, Breccia JD, et al. Experimental infection of rabbits (Oryctolagus cuniculus) with Brucella suis biovar 1 isolated from wild hares (Lepus europaeus). Vet Microbiol. 2012;156:439-42. http://dx.doi.org/ 10.1016/j.vetmic.2011.11.006

10. National Institute for Public Health and the Environment. Brucellosis [in Dutch]. Guideline of the National Coordination Centre for Communicable Diseases [cited 2017 Nov 10]. https://lci.rivm.nl/richtlijnen/brucellose

11. Olsen SC, Garin-Bastuji B, Blasco JM, Nicola AMSL. Brucellosis. In: Zimmerman JJ, editor. Diseases of swine, 10th ed. Ames (IA): Wiley-Blackwell; 2012. p. 697-708.

12. Akkermans JPWM, Bercovich Z. Brucellosis [in Dutch]. In: Verhoef P, editor. "Strict science and practical sense": a century Dutch Central Veterinary Institute 1904-2004. Rotterdam (the Netherlands): Erasmus Publishing; 2005. p. 234-238.

13. GfK. Pet food category insights [cited 2018 Jan 3] http://www.gfk.com/landing-pages/landing-pages-us/pet-insightscoop/pet-food-category-insights/

14. Glynn MK, Lynn TV. Brucellosis. J Am Vet Med Assoc. 2008;233:900-8. http://dx.doi.org/10.2460/javma.233.6.900

15. Kutlu M, Cevahir N, Erdenliğ-Gürbilek S, Akalın Ş, Uçar M, Sayın-Kutlu S. The first report of Brucella suis biovar 1 isolation in human in Turkey. J Infect Public Health. 2016;9:675-8. http://dx.doi.org/10.1016/j.jiph.2016.01.011

Address for correspondence: Els M. Broens, Department of Infectious Diseases and Immunology, Faculty of Veterinary Medicine, Utrecht University, Yalelaan 1, 3584 CL, Utrecht, the Netherlands; email: e.m.broens@uu.nl 